\title{
Biological evaluation of a series of thiosemicarbazones targeting the large subunit ribosomal protein eL42 from human 80 s ribosomes
}

\begin{abstract}
Background: Thiosemicarbazones are a family known as excellent chelators of enzyme cofactors or molecules with multiple biological activities including anti-tumor activity. ${ }^{1,2}$ Recent studies by Hountondji's team has revealed that the large subunit ribosomal protein eL42 (molecular weight of $12 \mathrm{kDa}, \mathrm{pHi}$ : 10,59) plays a functional role during the elongation step of translation ${ }^{3}$ and is over expressed in most cancers. ${ }^{4-6}$
\end{abstract}

Method: The method used was the one developed by Hountondji et al. ${ }^{7}$ which converts the $\mathrm{OH}$ functional groups at the positions 2' and 3' of adenine sugar of the CCA tRNA into a dialdehyde group by oxidation with $\mathrm{NaIO}_{4}$. Each aldehyde function can form a Schiff base with the amino group of the side chain of K53 residue of eL42, which results in a covalent bond after reduction with $\mathrm{NaBH}_{4}$ (crosslinking).

Results and discussion: The results of different experiments (the radioactivity, and the Western Blot technique) performed in this study show that 4 molecules (citral4-phenylthiosemicarbazone, piperitone-4-phenylthiosemicarbazone, the benzoin-4phenylthiosemicarbazone and 4-chlorobenzophenone-4-phenylthiosemicarbazone) out of 29 thiosemicarbazones tested showed activity by inhibiting the crosslinking reaction between tRNAox and eL42. These results suggest that the inhibition produced by thiosemicarbazones consist in masking the amino group of the side chain of Lys-53 located in the catalytic site of protein eL42, preventing Schiff base formation and the crosslinking reaction. These results are in accordance with those of Schneider-Poetsch et al. ${ }^{8}$ who found that certain compounds for example cycloheximide bind to the eL 42 protein through their carbonyl function. The weaker effects of benzoin-4-phenylthiosemicarbazone and 4-chlorobenzophenone-4phenylthiosemicarbazone as compared with citral-4-phenylthiosemicarbazone and piperitone-4- phenylthiosemicarbazone are likely to reflect the inaccessibility of the $\mathrm{NH} 2$ of Lys-53 of eL 4 to the thiocarbonyl groups $(\mathrm{C}=\mathrm{S})$ of these thiosemicarbazones because of steric hindrance. Finally, binding assays on Biacore 3000 confirmed interactions between active molecules and the human eL42 protein.

Conclusion: The inhibitory action of thiosemicarbazones on the interaction between the protein eL42 and tRNAox prevents formation of a Schiff base between the $\varepsilon$-amino group of Lys-53 and an aldehyde group of tRNAox. The Lys-53 residue of eL42 which contributes to the catalysis of peptide bond formation that represents the key step in the biosynthesis of proteins is a target of choice for small molecule inhibitors. Therefore, thiosemicarbazones can be used to reduce the rate of protein synthesis in order to block the hyper-proliferation of tumor cells (Figure 1).

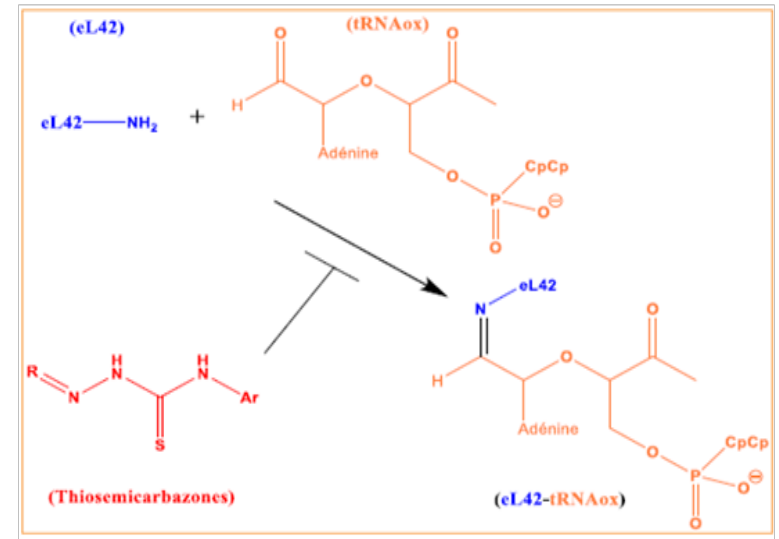

Figure I Graphical abstract.

Keywords: thiosemicarbazones, ribosomal protein e142, periodate-oxidized transfer rna, cancer, cycloheximide, SPR
Volume I Issue 6 - 2017

Horrhus D Houngue, ${ }^{1,2}$ Blanche S Aguida, ${ }^{2}$ Urbain C Kassehin,, 1,3 Jacques H Poupaert,, 1,3 Fernand A Gbaguidi,' Codjo Hountondji ${ }^{2}$

'Laboratory of Medicinal Organic Chemistry (MOCL), Benin

2 Research Unit UPMC UR6 "Enzymology of ARN", Sorbonne Universités UPMC Université Paris 06, France

${ }^{3}$ Louvain Drug Research Institute (LDRI), Université Catholique de Louvain, Belgium

Correspondence: Fernand A Gbaguidi, Laboratory of Medicinal Organic Chemistry (MOCL), Faculty of Health Sciences, 0I BP: 188 Cotonou, Benin, Tel (00229) 95066162 Email gbaguidifernand@gmail.com

Received: October 20, 2017 | Published: November 20, 2017 


\section{Introduction}

Cancer is a disease collectively characterized by cell proliferation (tumors) abnormally extended in a body tissue. Affecting any part of the body (organs, tissues), it is derived from a cell clone having acquired certain properties allowing cells to divide indefinitely. Statistical studies conducted by the World Health Organization (WHO) in 2012 count nearly 8.2 million deaths or $13 \%$ of deaths and about $70 \%$ of cancer mortality takes place in poor countries or in the process considering of development. Responsible for much of mortality, it is distributed in different types including: lung cancer (1.59 million deaths), liver cancer (745,000 deaths), stomach cancer (723,000 deaths), colorectal cancer (694,000 deaths), breast cancer (521,000 deaths), esophageal cancer (400 000 deaths) etc. WHO in 2012. In order to effectively fight against this disease, our laboratory has invested in the research of thiosemicarbazones, molecules obtained by the condensation of a substrate (thiosemicarbazides) and a reagent (carbonyl compound) and have interesting activities whose biological properties include: the antitrypanosomial activity ${ }^{1,9,10}$ but also important antimicrobial cytotoxicity. ${ }^{1,10}$

In order to better understand the functions played by the different actors, in the protein translation machinery, and identify the ribosomal components that contribute to this biological process, recent studies ${ }^{6}$ indicates the existence of eL42 protein formerly known as L36AL $(12 \mathrm{kDa}, \mathrm{pHi}=10.59)$ in the large $60 \mathrm{~S}$ subunit of the human ribosome. This protein was recently shown to contribute to the catalytic activity of the yeast ribosome at the elongation step of translation by promoting peptide bond formation (personal communication of Codjo Hountondji). This protein was found over expressed in almost all cancers ${ }^{4-6}$ and could be a target for chemotherapeutic molecules. Further studies subsequently showed that some chemotherapeutic molecules can be used to target the eL42 protein as for example cycloheximide or lactimidomycine which inhibit eL42 protein through lysine (K53) of the catalytic site, ${ }^{11}$ with their carbonyl functions $(\mathrm{C}=\mathrm{O})$. Based on the fact that bioisosterism thiosemicarbazones $(\mathrm{C}=\mathrm{S}$ function $)$ cytotoxic cancer cells of some strains are very similar chemotherapeutic molecules of carbonyl function inhibiting eL42, we discuss this point in this study to evaluate the mechanism of action of a series of thiosemicarbazones having cytotoxic activity (on cancer cells and trypanosomal) by a biological model using the ribosome as the target of anti-cancer molecules.

\section{Materials and methods}

\section{List of molecules}

All tested compounds were obtained making use of procedures and methods of analysis that were reported in previous works ${ }^{12-15}$

\section{Mechanism of crosslink formation}

The method used is the one developed by Professor Codjo Hountondji.

Principle: The chemical approach consists in oxidizing the alcohol functions of positions 2' and 3' of the sugar of adenine to the CCA end of the tRNA dialdehyde. Output connections can be created in contact with the $\mathrm{NH}_{2}$ function of the lysine residue 53 (K53) of the eL42 protein to form a Schiff base this resulting in a crosslink (Figure 2).

In this study 29 thiosemicarbazones and 2 negative controls were prepared in eppendorf tubes, at concentrations $100 \mathrm{mM}(\mathrm{S} 1)$ according to the quantity (mass and volume) entered in Table 1. S1 is diluted with DMSO to $20 \mathrm{mM}$ (S2). The thiosemicarbazone S3 solution is obtained at $1 \mathrm{mM}$ in the dilution mixture from (S2).

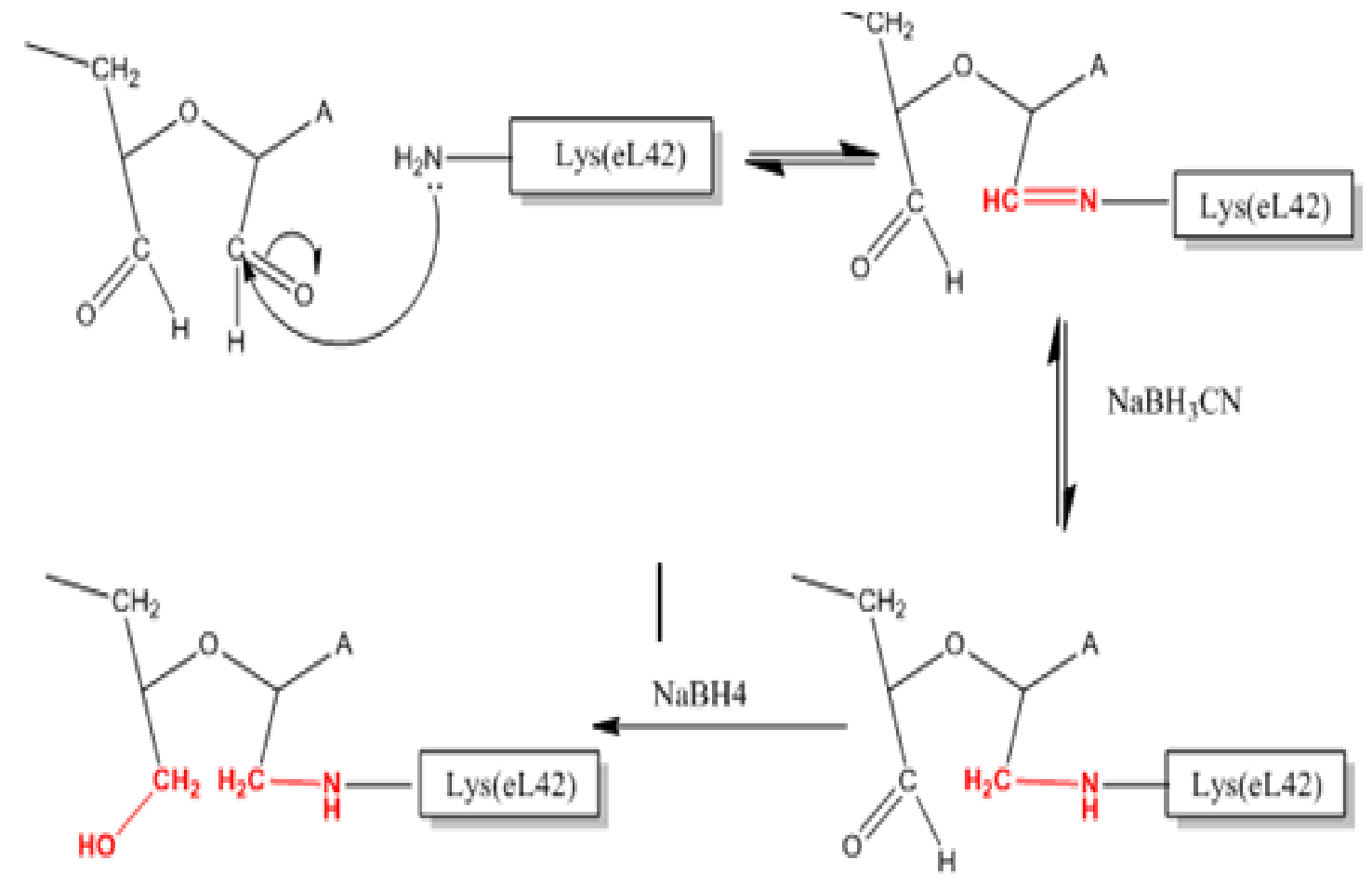

Figure 2 Diagram showing the formation and the reduction of the Schiff base (ChemDraw). 
Table I Summary of the molecules used

\begin{tabular}{|c|c|c|c|c|c|}
\hline Order & Compounds & Molecular structures & Weight (mg) & $\begin{array}{l}\text { Volume of } \\
\text { DMSO }(\mu \mathrm{l})\end{array}$ & $\begin{array}{l}\text { Concentration } \\
(\mathrm{mM})\end{array}$ \\
\hline I & UCK-33 & & 3 & 100 & 100 \\
\hline 2 & UCK-32 & & 4,2 & 90 & 100 \\
\hline 3 & UCK-4I & & 3,3 & 98,8 & 100 \\
\hline 4 & UCK-42 & & 3,3 & 100 & 100 \\
\hline 5 & UCK-3I & & 3 & 90 & 100 \\
\hline 6 & UCK-I52 & & 3,1 & 103,3 & 100 \\
\hline 7 & UCK-II & & 3,1 & 103,33 & 100 \\
\hline 8 & UCK-II8 & & 3,3 & 110 & 100 \\
\hline
\end{tabular}


Table Continued..

\begin{tabular}{|c|c|c|c|c|c|}
\hline Order & Compounds & Molecular structures & Weight (mg) & $\begin{array}{l}\text { Volume of } \\
\text { DMSO }(\mu \mathrm{I})\end{array}$ & $\begin{array}{l}\text { Concentration } \\
(\mathrm{mM})\end{array}$ \\
\hline 9 & $\begin{array}{l}\text { UCK- } \\
\text { IO(negative } \\
\text { control) }\end{array}$ & & 3,4 & 113,3 & 100 \\
\hline 10 & UCK- 159 & & 3,1 & 103,33 & 100 \\
\hline II & UCK-I03 & & 3 & 100 & 100 \\
\hline 12 & $\begin{array}{l}\text { UCK- } \\
\text { I49(negative } \\
\text { control) }\end{array}$ & & 3,3 & 110 & 100 \\
\hline 13 & UCK-16I & & 3,1 & 103,33 & 100 \\
\hline 14 & UCK-36 & & 3 & 100 & 100 \\
\hline 15 & UCK-I7 & & 2,3 & 100 & 100 \\
\hline 16 & UCK-3 & & 3,5 & 101,61 & 100 \\
\hline 17 & UCK-8 & & 3,1 & || $5,0 \mid$ & 100 \\
\hline 18 & UCK-19 & & 3 & 104,1 & 100 \\
\hline
\end{tabular}


Table Continued..

\begin{tabular}{|c|c|c|c|c|c|}
\hline Order & Compounds & Molecular structures & Weight (mg) & $\begin{array}{l}\text { Volume of } \\
\text { DMSO }(\mu \mathrm{l})\end{array}$ & $\begin{array}{l}\text { Concentration } \\
(\mathrm{mM})\end{array}$ \\
\hline 19 & UCK-I2 & & 3 & II 4,7 & 100 \\
\hline 20 & UCK-37 & & 3 & 100 & 100 \\
\hline 21 & UCK-39 & & 3 & 100 & 100 \\
\hline 22 & UCK-24 & & 3 & 76,7 & 100 \\
\hline 23 & UCK-25 & & 3,1 & 103,3 & 100 \\
\hline 24 & UCK-20 & & 3 & 80,97 & 100 \\
\hline 25 & UCK-I58 & & 3,1 & 103,33 & 100 \\
\hline 26 & UCK-23 & & 3 & 77,62 & 100 \\
\hline 27 & UCK-6 & & 3,2 & 119,2 & 100 \\
\hline
\end{tabular}


Table Continued..

\begin{tabular}{|c|c|c|c|c|c|}
\hline Order & Compounds & Molecular structures & Weight (mg) & $\begin{array}{l}\text { Volume of } \\
\text { DMSO }(\mu \mathrm{l})\end{array}$ & $\begin{array}{l}\text { Concentration } \\
(\mathrm{mM})\end{array}$ \\
\hline 28 & UCK-5 & & 3,1 & 109 & 100 \\
\hline 29 & UCK-I57 & & 3 & 100 & 100 \\
\hline 30 & UCK-22 & & 3 & 81 & 100 \\
\hline 31 & UCK-I60 & & 3,4 & 113,33 & 100 \\
\hline
\end{tabular}

\section{Biological part}

\section{Ribosomes, mRNA, tRNAs and periodate-oxidized tRNA}

40S and 60S ribosomal subunits with intact rRNAs were isolated from unfrozen human placenta15. Prior to use, the subunits were re-activated by incubation in binding buffer A $(50 \mathrm{mM}$ Tris- $\mathrm{HCl}$, $\mathrm{pH} 7.5,100 \mathrm{mM} \mathrm{KCl}, 10 \mathrm{mM} \mathrm{MgCl}$ and $0.5 \mathrm{mM}$ EDTA) at $37^{\circ} \mathrm{C}$ for $10 \mathrm{~min} .80 \mathrm{~S}$ ribosomes were obtained by association of the reactivated $40 \mathrm{~S}$ and $60 \mathrm{~S}$ subunits taken in the equimolar ratio. A short mRNA analogue (oligoribonucleotide GAA UUU GAC AAA) was purchased from Sigma Aldrich (Evry, France). tRNA-Asp from yeast was purified by counter-current chromatography, followed by separation by polyacrylamide gel electrophoresis. Its amino acid acceptance capacity was $1400 \mathrm{pmol} / \mathrm{A} 260$ unit. ${ }^{32} \mathrm{P}$-labeling of tRNA at the 5'end was carried out after dephosphorylation by alkaline phosphatase (Roche), in the presence of $\gamma$-[32P] ATP and polynucleotide kinase. Periodate-oxidized tRNA (tRNAox) was prepared as described previously. ${ }^{17}$

\section{tRNAox-labeling of ribosomal proteins}

Human $80 \mathrm{~S}$ ribosomal complex with $\left[{ }^{32} \mathrm{P}\right] \mathrm{tRNA}{ }^{\mathrm{Asp}} \mathrm{OX}$ at the P-site was obtained at $37^{\circ} \mathrm{C}$ in buffer containing $0.5 \mu \mathrm{M}$ of $80 \mathrm{~S}$ ribosomes and $5 \mu \mathrm{M}$ of the dodecaribonucleotide GAA UUU GAC AAA as an mRNA, in a total volume of $25 \mu \mathrm{l}$. These mixtures were preincubated for $5 \mathrm{~min}$ at $37^{\circ} \mathrm{C}$. The labeling reaction was initiated by the addition of $5 \mu \mathrm{M} \quad\left[{ }^{32} \mathrm{P}\right] \mathrm{tRNA}^{\mathrm{Asp}} \mathrm{Ox}$ and $5 \mathrm{mM}$ sodium cyanoborohydride $\left(\mathrm{NaBH}_{3} \mathrm{CN}\right)$ and the incubation was pursued for $1 \mathrm{~h}$. In the control experiment, $\left[{ }^{32} \mathrm{P}\right] \mathrm{tRNA}{ }^{\mathrm{Asp}} \mathrm{OX}$ at the P-site was replaced by intact $\left[{ }^{32} \mathrm{P}\right]$
tRNA $^{\text {Asp }}(5 \mu \mathrm{M})$ in the reaction mixture. For the protection of $80 \mathrm{~S}$ ribosomes against labeling with $\left[{ }^{32} \mathrm{P}\right] \mathrm{tRNA} \mathrm{R}^{\mathrm{Asp}} \mathrm{OX}, 15 \mu \mathrm{M}$ intact tRNA ${ }^{\mathrm{Asp}}$ was preincubated for $5 \mathrm{~min}$ at $37^{\circ} \mathrm{C}$ before the initiation of labeling reaction with $5 \mu \mathrm{M}\left[{ }^{32} \mathrm{P}\right] \mathrm{tRNA}{ }^{\mathrm{Asp}} \mathrm{Ox}$. tRNA ${ }^{\mathrm{Asp}} \mathrm{OX}$-red was obtained by preincubation of tRNA ${ }^{\text {Asp }} \mathrm{Ox}$ with $50 \mathrm{mM} \mathrm{NaBH}_{4}$ during $15 \mathrm{~min}$.

\section{Preparation of periodate-oxidized tRNA (tRNAox) from tRNA}

The tRNA dialdehyde derivative (tRNAox) was prepared by a mixture of tRNA $419 \mu \mathrm{M}$, with an excess of $\mathrm{NaIO}_{4}(\mathrm{C}: 0,5 \mathrm{M}) \mathrm{NH} 4 \mathrm{OAc}$ (C: $5 \mathrm{M}, \mathrm{pH} 5$ ) incubated at $4^{\circ} \mathrm{C}$ for 1 hour. Then oxidized tRNA was separated from $\mathrm{NaIO}_{4}$ salts on Sephadex ${ }^{\mathrm{TM}}$ G-25 (Distributor GE Healthcare). The tRNA analogue was precipitated with ethanol $/ \mathrm{NaCl}$ and conserved in ethanol $\left(96^{\circ} \mathrm{C}\right)$ at $-20^{\circ} \mathrm{C}$. For different tests using radioactive tRNA, this macromolecule was first radiolabeled before being oxidized.

\section{Western blot analysis}

The crosslink was made with the $60 \mathrm{~S}$ ribosomal subunit $(7 \mu \mathrm{M})$, tRNAox $(100 \mu \mathrm{M})$, in the crosslink buffer (10X) consisting of $\mathrm{MgCl}_{2}$ $(2 \mathrm{M})$, Tris- $\mathrm{HCl}(1 \mathrm{M}) \mathrm{pH}=8,8$. To this mixture was added $\mathrm{NaBH} 3 \mathrm{CN}$ $(0.05 \mathrm{M})$ and DEPC water, all incubated in a water bath at $37^{\circ} \mathrm{C}$. After 30 min of incubation, $\mathrm{NaBH} 4(0.4 \mathrm{M})$ was added to the mixture and then $5 \mu \mathrm{l}$ of leammli $(3 \mathrm{x})$ was added as a loading buffer for a final volume of approximately $16 \mu 1$. The resulting mixture was heated to $90^{\circ} \mathrm{C}$ for $5-10 \mathrm{~min}$. The resulting mixtures were then loaded onto a $12 \%$ SDS-polyacrylamide gel followed by migration with a 4 watt current generator for $80 \mathrm{~min}$ in Tris-Glycine-SDS buffer. After migration, the migrated proteins were transferred from the SDS 
polyacrylamide gel to the nitrocellulose membrane using the transfer buffer containing Tris-glycine-SDS and 20\% ethanol (3 watts for $90 \mathrm{~min}$ ). It was then blocked with 5\% milk in $1 \mathrm{X}$ PBS pH 7.4 and $0.1 \%$ Tween-20 (PBST) for 1 hour at room temperature, washed 4 times every $10 \mathrm{~min}$ and incubated in the primary antibody Mouse antiRPL36AL diluted to 1:10000 prepared in 1\% BSA/PBST buffer for 2 hours at room temperature followed by gentle stirring overnight. The membrane was then washed 3 times with PBST after 10 min each before incubation in secondary conjugated mouse antibody prepared in $1 \% \mathrm{BSA} / \mathrm{PBST}$ buffer for 1 hour at room temperature with gentle stirring. The membrane was then washed again 4 times after incubation in PBST after 10 min each before being then soaked in the Western ECL substrate for 3 minutes. The film was brought into contact with the membrane and then it was revealed by the peroxidase grafted to the secondary antibody which precipitates on the film in contact with its substrat.

\section{Binding assays on biacore}

The surface plasmon resonance (SPR) biosensor experiments were performed on a Biacore 3000 instrument (GE Healthcare). The purified His-tagged eL42 protein was immobilized on NTA sensor chip (GE Healthcare) to reach an immobilization level of the protein of 5,000-7,000 resonance units (RU), according to the manufacturer's recommendations. The protein eL42 and the molecule UCK-36 were diluted in HBS-EP GE Healthcare (10mM HEPES pH 7.4, 150mM $\mathrm{NaCl}, 3 \mathrm{mM}$ EDTA, $0.005 \%$ surfactant P20) containing $2 \mathrm{mM} \mathrm{MgCl}$. A reference surface without protein was prepared using the same procedure. Running buffer (10mM HEPES $\mathrm{pH} 7.4,150 \mathrm{mM} \mathrm{NaCl}$, $3 \mathrm{mM}$ EDTA, $0.005 \%$ surfactant P20) and binding buffer $(10 \mathrm{mM}$ HEPES pH 7.4, $150 \mathrm{mM} \mathrm{NaCl}, 2 \mathrm{mM} \mathrm{MgCl}_{2}$ ) were used. Between two binding assays at two different concentrations, the surface was regenerated by injection of $350 \mathrm{mM}$ EDTA at a flow rate of $15 \mu \mathrm{l} / \mathrm{min}$ and 30 s contact time, followed by a 5 min dissociation by washing at a continuous flow of the running buffer. The experimental data from individual kinetic binding experiments were overlaid and analyzed using BIAevaluation 4.1.F46 Bindi software (GE Healthcare) with 1:1 binding mode.

\section{Results}

\section{Results of hot trials « radioactivity »}

The results of the first hot tests on thiosemicarbazones entering this study are shown Figure 3. It shows the results of the effect of molecules (thiosemicarbazones) 1-5 on the formation of the Schiff base (crosslink) between tRNAox and the human ribosomal protein eL42. In view of these results, we retain that the presence of DMSO does not affect the formation of the crosslink and that the five first molecules are without effect on the formation of the Schiff base. Further work has been devoted to the evaluation of the effect of the remaining 24 thiosemicarbazones on the crosslink and the results are shown in Figure 4 \& 5 .

Lane Asp: control tRNAox alone; lane k: crosslinking control. A: lanes 6-11: molecules 6-11; B: lanes 12-18:molecules 12-18. The [ $\left.{ }^{32} \mathrm{P}\right]$ tRNA $^{\text {Asp }}$ Ox alone and the tRNA-eL42 covalent complex formed are shown.

The results in (Figure 4) show that the molecules 6, 7, 8, 9, 11, 12, 13,15 to 18 do not have inhibitory effect on the interaction between the protein and tRNAox. Molecule 10 leads to a partial effect. By contrast, molecule 14 completely inhibits the interaction between eL42 and tRNAox (Figure 4).

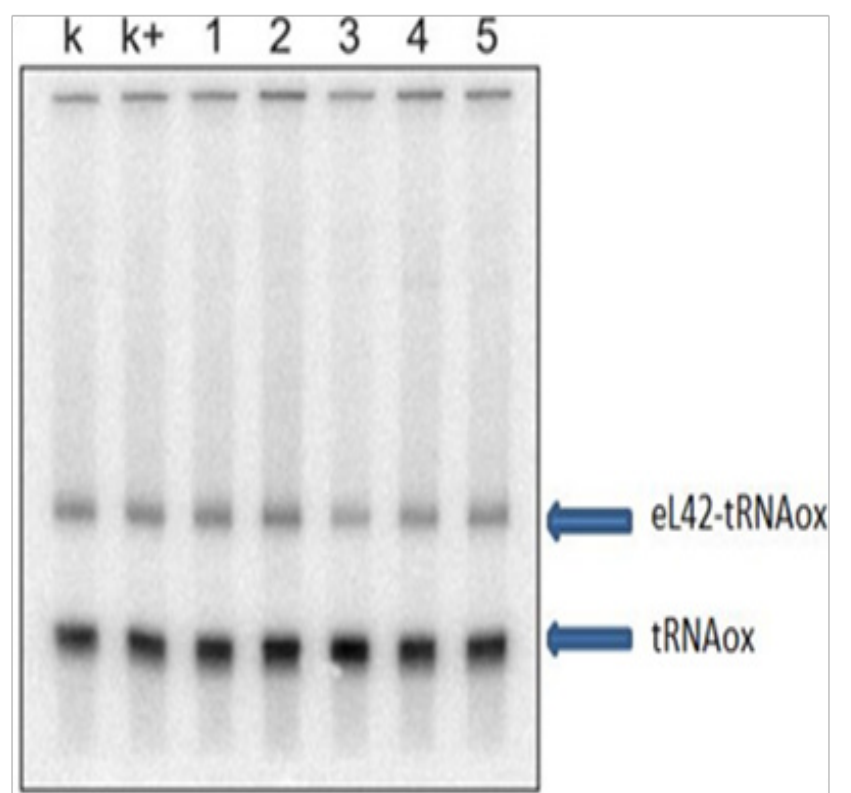

Figure $3 \mathrm{Gel}$ photo showing the results of molecules I-5 (Table I). Lane $\mathrm{k}$ : crosslinking control with DMSO; lane $\mathrm{k}+$ : crosslinking control with the crosslinking buffer described in Experimental Section. The $\left[{ }^{32} \mathrm{P}\right] \mathrm{tRNA}{ }^{\mathrm{Asp}}$ ox alone and the tRNA-eL42 covalent complex formed are shown.

A

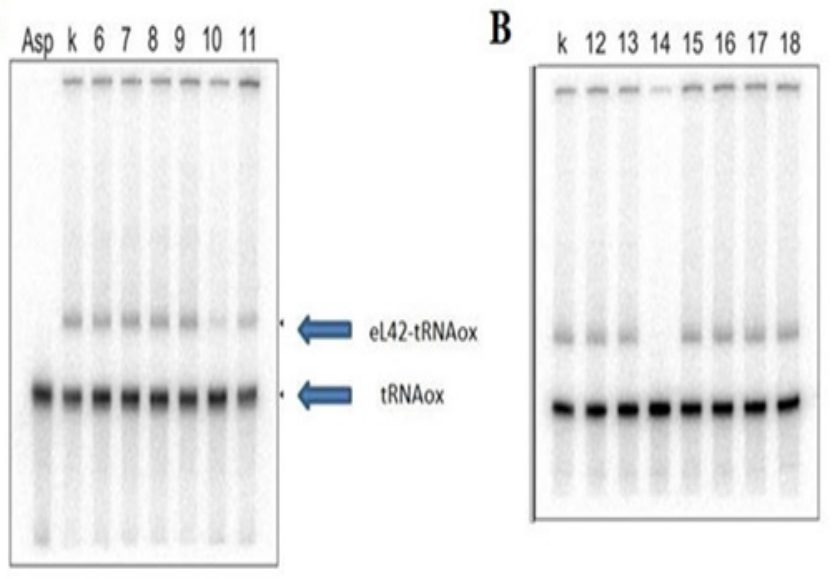

Figure 4 Pictures of two urea-PAGE gels showing the results of molecules $6-18$.

NB: molecules 9 and 12 which are not thiosemicarbazones are used as negative controls.

A: lanes 19-25: molecules 19-25; B: lanes 26-31: molecules 26-31. Lane k: cross linking control. These results show that the molecules 18, 19 and 21-30 have no inhibitory effect on the crosslink. By contrast, the molecule 31 has a partial effect, while the molecule 20 completely inhibits the interaction between eL42 and tRNAox.

In order to confirm the previous results, we repeated the experiment with 4 thiosemicarbazones molecules that have shown an effect on the formation of crosslink. They are referred to with a new numbering (1-4) (Figure 6).

\section{Results of trial by the technique of western blotting}

We chose to check and confirm our results obtained by radioactivity by another molecular method that enables specific protein detection on a membrane. 


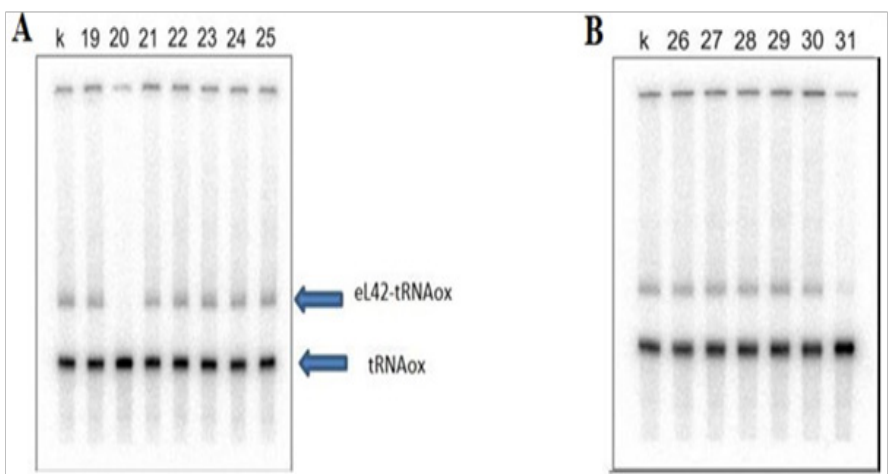

Figure 5 Photos of two urea-PAGE gels showing the results of molecules $|9-3|$.

A: lanes 19-25: molecules 19-25; B: lanes 26-31: molecules 26-31. Lane k: cross linking control.

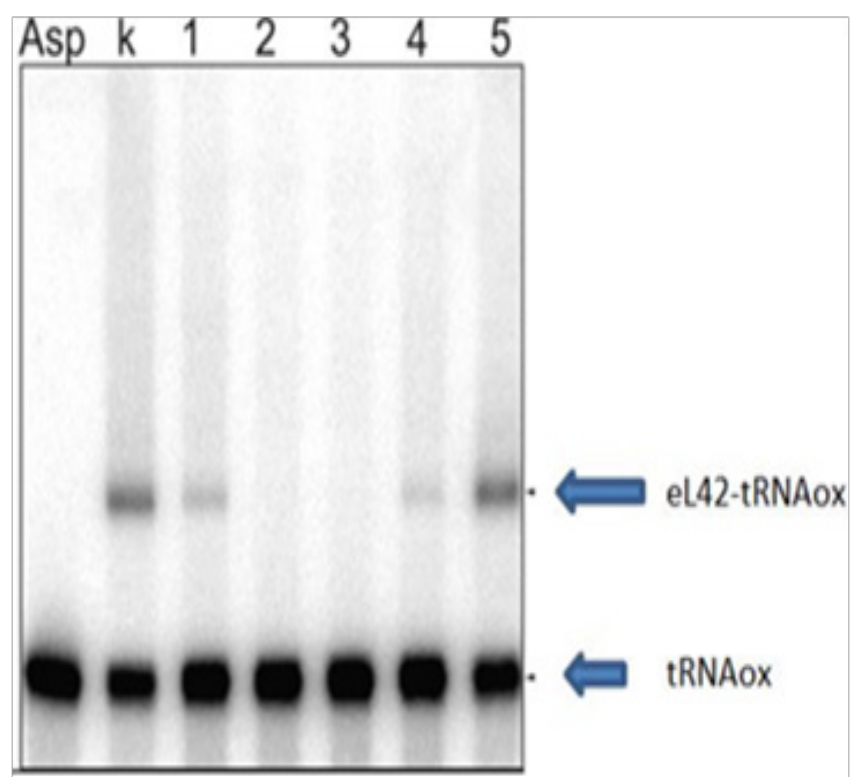

Figure 6 Gel picture showing the inhibitory action of the molecules (lane I: UCK-159, lane 2: UCK-36, lane 3: UCK-37 and lane 4:UCK-160) on the crosslink. Lane 5: UCK-II8 is used as a negative control. Lane k: crosslinking control. These results confirm those obtained above (Figure 2-4).

\section{Results of the binding assays on biacore}

Protection of eL42 by molecule UCK-36 against the reaction with tRNAox suggests that this molecule might interact with the ribosomal protein in situ on the human $80 \mathrm{~S}$ ribosome. The potential interactions between molecule UCK-36 and protein eL42 were evaluated. To determine the binding affinities of eL42 to molecule UCK-36, we carried out surface plasmon resonance (SPR) analyses with a Biacore biosensor, which provides real-time protein-molecules interaction data by measuring the change in refractive index at the surface of the sensor chip due to the interactions. Experimental data from individual kinetic binding experiments were analyzed and fitted using BIAevaluation software with 1:1 binding model, in accordance to the 1:1 stoichiometry of binding of the tRNA substrate to eL42 (Figure 7).

Kinetic and affinity constants for UCK-36, including association (ka or kon) and dissociation (kd or koff) rates and affinity constants $\left(\mathrm{K}_{\mathrm{D}}\right)$, as deduced from the analyses in Figure 8. The experimental errors on the $K_{D}$ were in the range $5-7 \%$ of the values. Kinetic and affinity constants for the interactions between UCK-36 and the protein eL42 were, $\mathrm{ka}=26.1 \times 10^{6} \mathrm{M}^{-1} \mathrm{~s}^{-1} ; \mathrm{kd}=2.14 \times 10^{-3} \mathrm{~s}^{-1} ; \mathrm{K}_{\mathrm{D}}=82.10^{-6} \mathrm{M}$

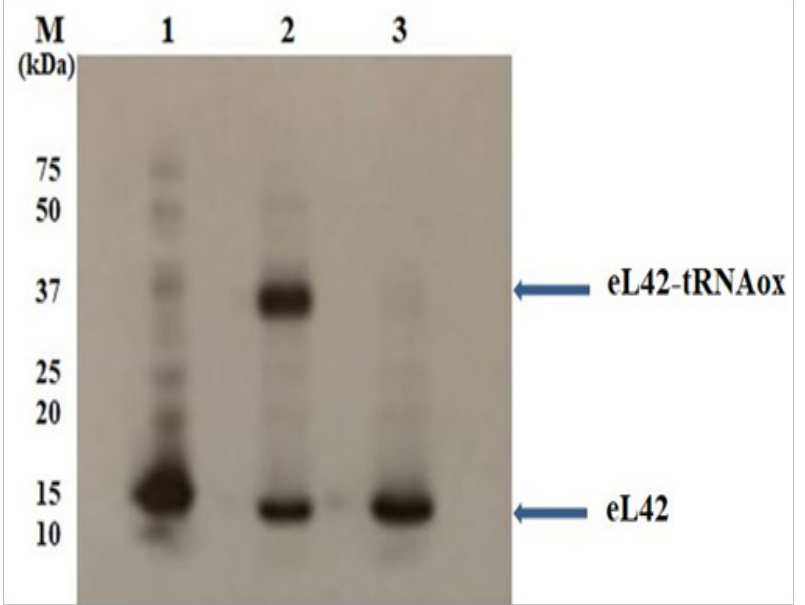

Figure 7 Auto radiographic analysis of the ribosomal protein eL42 detected with the anti-eL42 antibodies.

The eL42 protein was detected among the large 60S subunit ribosomal proteins as free eL42 in Lane I (Ribosome 60S), or the eL42-tRNAox covalent complex (crosslink) in lane 2 (Ribosome 60S + tRNAox). The inhibitory effect of UCK-36 molecule on the crosslink is shown in lane 3 (Ribosome $605+t R N A o x+U C K-36(I m M))$. The positions of marker proteins analyzed in parallel are also shown.

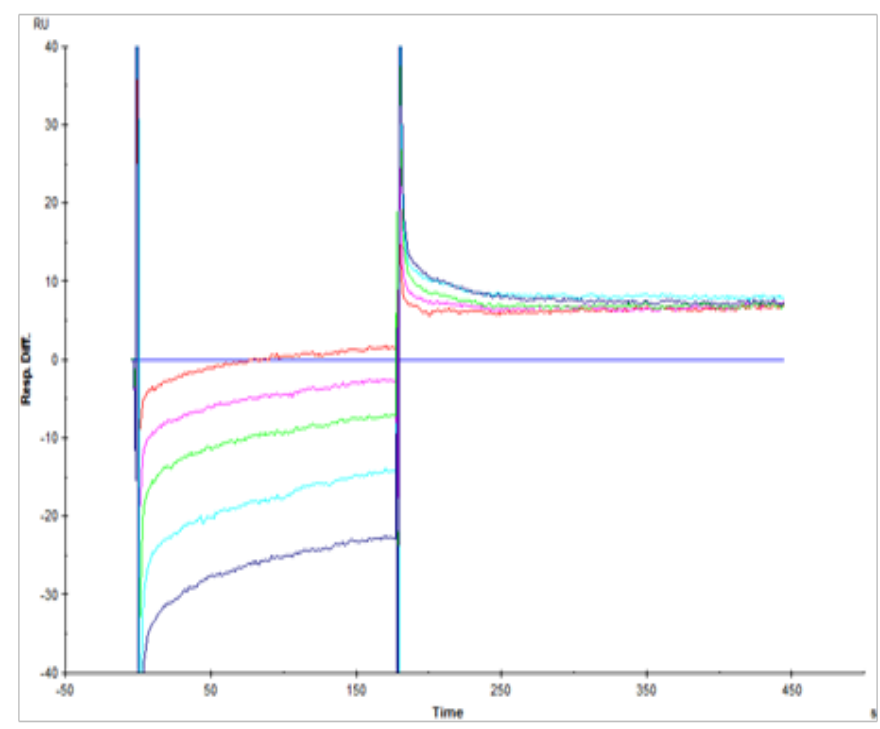

Figure 8 Kinetic measurement of eL42: UCK-36 interaction for various concentrations of UCK-36 $(0,200 \mu \mathrm{M}, 400 \mu \mathrm{M}, 600 \mu \mathrm{M}, 800 \mathrm{M}$ and $1000 \mu \mathrm{M})$ run over the chip surface.

\section{Discussion}

The use of thiosemicarbazones as small-molecule inhibitor targeting the large subunit ribosomal protein eL42 is designated by the fact that these molecules are analogous to other anti-tumor molecules that had been shown to inhibit eukaryotic translation elongation by targeting the $80 \mathrm{~S}$ ribosomes. These molecules are for example, mycalamide A or B, as well as the molecules of the family of glutarimides such as cycloheximide, lactimidomycin and streptimidone. ${ }^{18-20}$ In the case of cycloheximide, it was shown that 
one carbonyl group of this molecule is bound through a hydrogen bond to Lys-55 of eL42 in the crystal structure of $S$. cerevisiae $80 \mathrm{~S}$ ribosomes. ${ }^{11}$ In the present report, the molecular basis of the inhibition of the ribosome by the thiosemicarbazones is the nucleophilic attack of the nitrogen $\left(\mathrm{NH}_{2}\right)$ of Lys-53 of eL42 on the group $(\mathrm{C}=\mathrm{S})$ which is an electrophilic center ( $\mathrm{sp} 2$ carbon). Screening the inhibitory effects of thiosemicarbazones on the crosslinking with tRNAox (the reactive dialdehyde derivative of tRNA) of the large subunit ribosomal protein eL42 has enabled us to select 4 thiosemicarbazones exhibiting inhibition of the crosslinking reaction. The inhibition observed with these 4 thiosemicarbazones i.e. citral-4-phenyl-3thiosemicarbazone (UCK-36) piperitone-4-phenylthiosemicarbazone (UCK-37), the benzoin-4-phenylthiosemicarbazone (UCK-159) and 4-chlorobenzophenone-4-phenylthiosemicarbazone (UCK-160) can be explained by the fact that the molecules mask the $\mathrm{NH}_{2}$ group of the side chain of Lys-53 which reacts with an aldehyde group of tRNAox to form a Schiff base. Lys-53 is adjacent to the GGQ motif conserved in the eL42 of all eukaryotic 80 S ribosomes. ${ }^{21}$ This motif is identical to the universally conserved GGQ motif common for all class-1 translation termination factors responsible for stop codon recognition and for triggering hydrolysis of the P site-bound peptidyltRNA. ${ }^{22}$ Interestingly, the Lys-53 residue of the GGQTK motif was shown to play an essential role in peptide bond formation. Moreover, the Lys-53 residue has a $\mathrm{pKa}$ value of $6.9^{21}$ which is 3.5 units less than that of a normal lysyl residue $(\mathrm{pKa}=10.53)$. Therefore, the Lys53 residue located at the catalytic site is likely to be deprotonated at physiological $\mathrm{pH}$, giving the possibility of a nucleophilic attack of nitrogen on the nearby electrophilic group. The slight effects of the last two compounds (UCK-159 and UCK-160) on the crosslink compared to UCK-36 and 37 are explained by the difficulty of the nitrogen of lysine 53 to generate a nucleophilic attack on the electrophilic carbon $(\mathrm{C}=\mathrm{O})$ most probably because of steric effects by aryl groups or the intrinsic instability of the molecules.

The values of the constants of the kinetic studies carried out revealed interaction between the UCK-36 molecule and the human eL42 with an average association Ka (ka or kon which is $26.1 \times 10^{6}$ $\mathrm{M}^{-1} \mathrm{~S}^{-1}$ ), the rate (Kd or koff which is $2.14 \times 10^{-3} \mathrm{~s}^{-1}$ ), and binding affinity defined by $\mathrm{K}_{\mathrm{D}}$ which is $82.10^{-6} \mathrm{M}$ or $82 \mu \mathrm{M}$ ).

Since the resonance unit (RU) that is the reflect of the refractive index is much greater for the analyte with several sites of interaction on the ligand leading to a large exchange surface between the two partners, the $\mathrm{K}_{\mathrm{D}}$ values defining the affinity between eL42 and translation factors or tRNA or rRNA are expected to be much lower (in the $\mathrm{pM}$ or $\mathrm{nM}$ range $)^{23}$ than that of small molecules. In accordance with this observation, the only probable sites of interaction between UCK-36 and the $\mathrm{rP}$ eL42 are the $\mathrm{NH}_{2}$ end of the Lys-53 residue and the thio carbonyl $(\mathrm{C}=\mathrm{S})$ function of the thiosemicarbazone (UCK36 ). In view of all the above, we can draw the conclusion that UCK36 interacts with $\mathrm{rP}$ eL42, which confirms the results previously obtained with the tests on the crosslink inhibition between eL42 and tRNAox. Note that to our knowledge this is the first time ever that a study on the interaction between a thiosemicarbazone and the protein (eL42) involved in the proliferation of most cancer cells has been performed. Since the anti-tumor activity of the thiosemicarbazones family had been shown to be related to their capability to chelate enzyme cofactors, the demonstration in the present report that these molecules can be used to reduce the rate of protein synthesis in order to block the hyper-proliferation of tumor cells, suggests that the thiosemicarbazones family can be considered as multi hit anti-tumor compounds. It is generally accepted that the latter molecules represent the most promising anticancer therapeutic agents.

\section{Acknowledgements}

We are grateful to Drs. Konstantin Bulygin, Soria Baouz and Anne Woisard for advices and fruitful discussions. We gratefully thank Dr. Tahar Bouceba of the Plateforme d'interactions moléculaires, Institut de Biologie Paris Seine (IBPS) for his constant interest for this work and for technical assistance.

Authors' contribution HDH, BSA and UCK performed the experiments; JHP, FAG and $\mathrm{CH}$ designed the experiments, interpreted the data and wrote the manuscript. All authors red the manuscript and discussed and commented the results.

\section{Conflict of interest}

The author declares no conflict of interest.

\section{References}

1. Sakirigui A, Kpoviessi Salomé DS, Gbaguidi F, et al. Selective Trypanocide Activity of Some Substituted Thiosemicarbazones of Citral From Benin Cymbopogon Citrates Essential Oil and their Toxicity Against Artemia Salina Leach. IJRRAS. 2012;12(3):454-462.

2. Kulandaivelu U, Shireesha B, Mahesh C, et al. Synthesis Antimicrobial and Anticancer Activity of N'-Arylmethylidene-Piperazine-1-Carbothiohydrazide. Med Chem Res. 2013;22(6):2802-2808.

3. Hountondji C, Bulygin K, Woisard A, et al. Lys53 of ribosomal protein L36AL and the CCA end of a tRNA at the P/E hybrid site are in close proximity on the human ribosome. Chembiochem. 2012;13(12):17911797.

4. Kim JH, You KR, Kim IH, et al. Over-expression of the ribosomal protein L36a gene is associated with cellular proliferation in hepatocellular carcinoma. Hepatology. 2004;39(1):129-138.

5. Shenoy N, Kessel R, Bhagat TD, et al. Alterations in the ribosomal machinery in cancer and hematologic disorders. J Hematol Oncol. 2012;5:32.

6. Baouz S, Woisard A, Sinapah S, et al. The human large subunit ribosomal protein L36A-like contacts the CCA end of P-site bound tRNA. Biochimie. 2009;91(11-12):1420-1425.

7. Hountondji C, Fayat G, Blanquet S. Complete inactivation and labeling of methionyl-tRNA synthetase by periodate-treated initiator tRNA in the presence of sodium cyanohydridoborate. Eur J Biochem. 1979;102(1):247-250.

8. Schneider-Poetsch T, Ju J, Eyler DE, et al. Inhibition of eukaryotic translation elongation by cycloheximide and lactimidomycin. Nat Chem Biol. 2010;6(3):209-217.

9. Fatondji HR, Gbaguidi F, Kpoviessi S, et al. Synthèse, Caractérisation et Etude de Propriétés Antimicrobiennes de la Semicarbazone et la Thiosemicarbazone de la Carvone. J Soc Ouest-Afr Chim. 2010;30:1117.

10. Glinma B, Kpoviessi SDS, Gbaguidi FA, et al. Synthesis, Characterization, trypanosomal activities on trypanosoma brucei brucei and toxicity against Artemia salina Leach of N(4)-aryl semicarbazones and thiosemicarbazones. J Chem Pharm Res. 2012;4(2):1016-1021.

11. Garreau de Loubresse N, Prokhorova I, Holtkamp W, et al. Structural basis for the inhibition of the eukaryotic ribosome. Nature. 2014;513(7519):517-522. 
12. Kasséhin UC, Gbaguidi FA, Kapanda NC, et al. Electronic and steric effects in the control of the Anilinium chloride catalyzed condensation reaction between Aldones and 4-Phenylthiosemicarbazide. African Journal of Pure and Applied Chemistry. 2013;7(9):325-329.

13. Kasséhin UC, Gbaguidi FA, Kapanda CN, et al. Solvent effect and catalysis in the synthesis of thiosemicarbazone derivatives from ketones and 4'-phenylthiosemicarbazide. Afr J of Pure and Appl Chem. 2014;8(8):110-115.

14. Kasséhin UC, Gbaguidi FA, McCurdy CR, et al. Synthesis of antitrypanosomal thiosemicarbazones using anthranilic acid as an innovative Green nucleophilic catalyst. J Chem Pharm Res. 2014;6(10):607-612.

15. Kasséhin UC, Gbaguidi FA, McCurdy CR, et al. Trypanocidal activity of a thioacyl-thiosemicarbazide derivative associating both immunostimulating thalidomide and anti-parasitic thiosemicarbazides pharmacophores. J Chem Pharm Res. 2015;7(7):48-55.

16. Matasova NB, Myltseva SV, Zenkova MA, et al. Isolation of ribosomal subunits containing intact rRNA from human placenta: estimation of functional activity of 80S ribosomes. Anal Biochem. 1991;198(2):219223.

17. Fayat G, Hountondji C, Blanquet S. Methionyl-tRNA synthetase from Escherichia coli: Inactivation and labeling by periodate-treated initiator tRNA. Eur J Biochem. 1979;96(1):87-92.
18. Gürel G, Blaha G, Steitz TA, et al. Structures of triacetyloleandomycin and mycalamide a bind to the large ribosomal subunit of Haloarcula marismortui. Antimicrob Agents Chemother. 2009;53(12):5010-5014.

19. Schneider-Poetsch T, Ju J, Eyler DE, et al. Inhibition of eukaryotic translation elongation by cycloheximide and lactimidomycin. Nat Chem Biol. 2010;6(3):209-217.

20. Dang Y, Schneider Poetsch T, Eyler DE, et al. Inhibition of eukaryotic translation elongation by the antitumor natural product mycalamide $\mathrm{B}$. RNA. 2011;17(8):1578-1588.

21. Hountondji C, Bulygin K, Créchet JB, et al. The CCA-end of P-tRNA contacts both the human RPL42 and the A-site bound translation termination factor eRF1 at the peptidyl tranferase center of the human $80 \mathrm{~S}$ ribosome. Open Biochem J. 2014;8:52-67.

22. Frolova LY, Tsivkovskii RY, Sivolobova GF, et al. Mutations in the highly conserved GGQ motif of class 1 polypeptide release factors abolish ability of human eRF1 to trigger peptidyl-tRNA hydrolysis. RNA. 1999;5(8):1014-1020.

23. Eustache S, Créchet JB, Bouceba T, et al. Functional role for the monomethylated Gln-51 and Lys-53 residues of the 49GGQTK53 motif of eL42 from human 80S ribosomes. Open Biochem J. 2017;11:8-26. 